\title{
Economics
}

The Open-Access, Open-Assessment E-Journal

Vol. 14, 2020-9 | February 26, 2020 | http://dx.doi.org/10.5018/economics-ejournal.ja.2020-9

\section{Job duration and inequality}

\section{Siyan Chen and Saul Desiderio}

\begin{abstract}
As suggested by recent empirical evidence, one of the causes behind the widespread rise of inequality experienced by OECD countries in the last few decades may have been the increased flexibility of labor markets. The authors explore this hypothesis through the analysis of a stock-flow consistent agent-based macroeconomic model able to reproduce with good statistical precision several empirical regularities. They employ three different sensitivity analysis techniques, which indicate that increasing job contract duration (i.e. decreasing flexibility) has the effect of reducing income and wealth inequality. However, the authors also find that this effect is diminished by tight monetary policy and low credit supply. The last result suggests that the final outcome of structural reforms aimed at changing labor flexibility can depend on the macroeconomic environment in which these are implemented.
\end{abstract}

JEL $\quad$ C15 C63 D31 E50 J01 J41

Keywords Economic inequality; labor market flexibility; monetary policy; agentbased models; sensitivity analysis

\section{Authors}

Siyan Chen, Shantou University, China

Saul Desiderio, Shantou University, China, saul@stu.edu.cn

Citation Siyan Chen and Saul Desiderio (2020). Job duration and inequality. Economics: The Open-Access, Open-Assessment E-Journal, 14 (2020-9): 1-26. http://dx.doi.org/10.5018/economics-ejournal.ja.2020-9 


\section{Introduction}

The widespread rise of income and wealth inequality is certainly one of the most conspicuous economic phenomena of the last few decades. As convincingly suggested by Piketty (2014), this tendency could even be an intrinsic feature of capitalist economies due to the continuous process of capital accumulation and reinvestment. To same conclusions seems to lead Scheidel (2017), who points out that historic periods of substantial reduction in inequality have always been caused by such catastrophic events as wars, revolutions, state collapses and plagues. Besides the intrinsic mechanisms of the capitalist economic system, however, also more accidental causes may well have played an important role in increasing inequalities in recent periods. Among them are certainly skill-biased technological progress and globalization, which have conspired to reduce the income share represented by wages, especially those of low-skilled workers (Atkinson, 2015, ch. 3; Autor et al., 2008). In addition, crisis of Welfare State and fiscal policies generally more oriented to less progressive tax regimes have also contributed to the general surge in inequality (OECD, 2011; Forster and Toth, 2015).

Less attention has been drawn by labor market reforms, which indeed have been much debated but not because of their potential negative impact on inequality, at least until recently. This kind of reforms is in general aimed at removing frictions and rigidities impeding the smooth functioning of demand and supply of labor and therefore the achievement of full employment. In particular, an important goal pursued by labor market reforms in OECD Countries has been that of increasing the degree of flexibility of employment relationships between employer and employee (OECD, 1994).

Essentially, we can distinguish two types of flexibility: internal and external (Atkinson, 1985). The former indicates adjusting working times and intra-firm workforce reallocation, whereas the latter refers basically to temporary (fixed-duration) job contracts and inter-firm workforce reallocation.

External flexibility enabled by temporary jobs is pursued because it decreases firing costs. As a consequence, from a microeconomic standpoint it may help worker reallocation among firms, with positive effects on productivity; and from a macroeconomic perspective it may increase the willingness to hire by firms, thus reducing unemployment. The idea that temporary jobs can reduce unemployment consolidated during the 90's of the XX century, when the highly deregulated American job market used to record unemployment rates substantially lower than those produced by the much more regulated (i.e. "rigid") European counterparts. Besides obvious political and theoretical reasons based on the neoclassical analysis of the labor market, this view was also supported by a number of empirical studies (such as for instance Lazear, 1990; OECD, 1994; Scarpetta, 1996; Siebert, 1997), which systematically found positive correlations between unemployment and measures of labor market rigidity.

Substantial empirical evidence has documented that unemployment disproportionately falls upon low-income groups, consequently widening the income gap between different groups (Carpenter and Rogers, 2004). Thus, as temporary job contracts are supposed to foster growth and reduce unemployment, they can also be thought to be conducive to lower inequality. However, more recent empirical studies have cast doubts on the reliability of earlier works, and the evidence 
about labor market rigidities and unemployment (and, as a consequence, about rigidities and inequality) is now at best equivocal. Indeed, several recent studies suggest that more rigid labor regulations may actually decrease inequality (for a review of recent works see e.g. Brancaccio et al., 2018).

The presence of such contrasting evidence hints that the truth might simply lie in the middle. In other words, both very flexible and very rigid labor markets might hamper growth and increase inequality. A second possible reason is that the impact of labor flexibility on the economy could be influenced by other factors. If such an interaction exists, therefore, labor market reforms may have very different effects according to the particular economic environment in which they are implemented. Thus, the aim of this paper is to investigate the plausibility of such hypotheses, with a focus on the effects of temporary job contracts on personal income and wealth inequality.

Our investigation will be carried out through an extensive analysis of a stock-flow consistent agent-based macro model already presented in Chen and Desiderio (2018). Stock-flow consistency, which has witnessed increasing application in agent-based literature in recent years (e.g. Cincotti et al., 2010; Delli Gatti and Desiderio, 2015; Riccetti et al., 2015; Caiani et al., 2016; Dosi et al., 2017; Mazzocchetti et al., 2018), basically consists in the implementation of precise accounting rules, and is of particular importance to our scope as it provides a correct link between income and wealth.

The analysis of inequality in the context of agent-based macroeconomics has gained momentum in recent years. For instance, Desiderio and Chen (2016), Riccetti et al. (2016) and Russo et al. (2016) study how functional and personal income distributions are affected by financial factors, while Dosi et al. (2013), Dosi et al. (2015) and Chen and Desiderio (2018) analyze the interaction between inequality and monetary policy. Two works that get closer to the present paper are Dosi et al. $(2017 ; 2018)$, where the authors find a negative correlation between labor market rigidity and inequality, probably caused by the positive effect that longer job contracts exert on employment through an increased macroeconomic coordination. This result was also found in Desiderio et al. (2015), where short contract duration generally increases the likelihood of having coordination failures and, thus, unemployment. ${ }^{1}$ Results of this kind were partly found also in mainstream labor search-and-matching literature, which however has the limitation of taking a microeconomic perspective and thus of ignoring the interconnections among different markets (e.g. Cahuc and Postel-Vinay, 2002).

In the model that we use here, firms, households and one bank interact on the markets for labor, credit and a consumption good. Households have two income sources: labor income (wages) and capital income (interests). The former comes from temporary jobs and the latter is the result of the investment of households' accumulated savings in financial assets sold by the bank. Temporary jobs will be the major concern of our analysis, as changes in the job contract length (that is the external flexibility of the labor market) will affect unemployment and worker reallocation among firms. Both unemployment and reallocation are important drivers of income inequality. Whereas the role of the former is pretty obvious, the way the latter works is less straightforward. When in

1 The analysis in Dosi et al. $(2017 ; 2018)$, however, focuses more on the rigidity of the wage determination process than on the duration of job contracts, which is either infinite (their Fordist scenario) or one-period long (their Competitive scenario), while our analysis encompasses many degrees of contract duration. 
fact job contracts are shorter, in our model firms have to increase wages more often in order to hoard labor. As a consequence, competition among firms on the labor market increases and highwage employers will be more successful than others. This will contribute to rise both average wage and wage dispersion.

The rest of the paper is organized as follows. In Section 2 we present the model along with its basic properties. In spite of its relative simplicity, we will show that our model is able to match a good deal of empirical evidence, performing particularly well in replicating business cycle stylized facts. In Section 3 we will study the relationship between job contract duration and inequality using three techniques: a local sensitivity analysis (LSA), a global sensitivity analysis (GSA) and a third kind involving only two parameters at time that we take the liberty to label 'pairwise' sensitivity analysis (PSA). The latter two will be carried out employing the approach proposed by Chen and Desiderio (2018), which economizes on the computational effort necessary to perform global and local sensitivity analysis. In general, we will see that the three techniques point at an inverse relationship between contract duration and inequality, although non-linearities cannot be ruled out. Moreover, PSA reveals that contract duration interacts with other parameters as formerly guessed, in particular with the policy rate and the bank lending attitude. Basically, what we find is that, ceteris paribus, a tighter monetary policy and a lower credit supply reduce the ability of longer job contracts to curb inequality. The last finding suggests that the final effect of institutional reforms may depend also on the macroeconomic context and warns against piecemeal policy making. Although this is a mere computational result, it is also an empirically testable prediction that deserves to be further investigated. Finally, Section 4 concludes.

\section{The model and its properties}

The model is the abstraction of a closed economy populated by firms, households and one commercial bank, while Government and central bank are not explicitly modeled. There are three markets: for labor, consumption goods and bank loans, plus an implicit market for bank deposits. Agents enter markets according to a decentralized search-and-matching process, and their behavior follows simple adaptive rules based on small amount of private information. Households represent the supply side in the labor market and the demand side in the goods market. Firms are on the demand side in the labor and credit market and on the supply side in the goods market. Both households and firms hold deposits at the bank. On its turn, the bank receives deposits and extend loans to firms. In what follows we will first describe the agents and then the markets. Finally, we will present some simulation results.

\subsection{The agents}

In this section we are going to give a general description of the agents' characteristics and of the sequence of actions they take every period.

Agents' state variables can be represented at any point in time by their balance sheets (stocks), which reflect all the market transactions undertaken (flows). The relationship between stocks and flows is regulated by rules that follow coherent accounting principles. This stock-flow consistency 
Table 1: Balance sheets

\begin{tabular}{ccccc}
\hline & Households & Firms & Bank & Total \\
\hline Deposits & $D_{h}$ & $D_{f}$ & $-\left(D_{h}+D_{f}\right)$ & 0 \\
Reserves & & & $H$ & $H$ \\
Loans & & $-L$ & $L$ & 0 \\
\hline Total & $E_{h}$ & $E_{f}$ & $E_{b}$ & $H$ \\
\hline
\end{tabular}

is implemented as it increases the degree of realism and reliability of the model. In particular, it is very important for our analysis because it assures that income and wealth inequality are not affected by an incorrect updating of individual variables. Aggregate balance sheets are reported in Table 1. Items with positive sign are assets, whereas those with negative sign are liabilities.

Households and firms' deposits (liquid assets) are denoted by $D_{h}$ and $D_{f}$ respectively, whereas $L$ represents bank loans and $H$ is the monetary base $\left(M_{0}\right)$. The difference between assets and liabilities constitutes the net worth (equity), which is denoted by $E_{h}, E_{f}$ and $E_{b}$ for households, firms and bank respectively. In the aggregate assets and liabilities must sum to zero, thus the accounting identity

$$
E_{h}+E_{f}+E_{b}=H
$$

holds. We suppose that there is no currency, and that transactions are settled directly by bank deposits. For the sake of simplicity we can therefore set $H=0$.

The evolution of the balance sheets is due to market transactions. The corresponding flows are reported in Table 2, which we construct along the lines of the recent SFC-ABM literature (e.g. Caiani et al., 2016). Items representing outflows of value are identified by the minus sign: $C$ is consumption spending, $I n$ is the change in inventories (such that total production is $Y=$ $C+I n), w N$ is the wage bill, $\Psi$ are taxes levied on the households by the Government to refinance defaulted firms, $i$ is the loan interest rate and $r$ is the return on bank deposits. Notice that as for firms and bank we distinguish between flows relative to the current account (column CA) and flows relative to the capital account (column KA). As the economy is closed, savings must be equal to investments, that is

$$
S=S_{h}+S_{f}+S_{b}=I
$$

where $S_{h}=\Delta E_{h} ; S_{f}=\Delta E_{f} ; S_{b}=\Delta E_{b}$. As there is no physical capital, investments coincide identically with the net change in inventories. However, we assume that firms do not retain unsold goods $(I n)$, so the net change in inventories is zero $(I n-I n=0)$. As a consequence, also total savings are always equal to zero.

Market transactions are the outcome of the actions that agents repeat every period $t=1 \ldots T$. The sequence of these actions is summarized below:

1. The labor market opens. Firms decide prices, quantities and wage offers, then post vacancies. Unemployed workers send applications to a fixed number of potential employers, choosing the one offering the highest wage. 
Table 2: Flow of funds

\begin{tabular}{ccccccc}
\hline & Households & \multicolumn{2}{c}{ Firms } & \multicolumn{2}{c}{ Bank } & Total \\
& & CA & KA & CA & KA & \\
\hline Goods & $-C$ & $C$ & & & & 0 \\
New inventories & & In & $-I n$ & & & 0 \\
Depreciation & & $-I n$ & In & & & 0 \\
Wages & $w N$ & $-w N$ & & & & 0 \\
Loan interests & & $-i L$ & & $i L$ & & 0 \\
Deposit interests & $r D_{h}$ & & & $-r D_{h}$ & & 0 \\
New loans & & & $\Delta L$ & & $-\Delta L$ & 0 \\
New deposits & $-\Delta D_{h}$ & & $-\Delta D_{f}$ & & $\Delta D$ & 0 \\
Taxes & $-\Psi$ & $\Psi$ & & & & 0 \\
\hline Total & 0 & 0 & 0 & 0 & 0 & 0 \\
\hline
\end{tabular}

The credit market opens. Firms whose internal financial resources are insufficient to pay wages try to get a loan from the bank. The bank pays interests on households' deposits. The credit market closes.

Firms whose resources are still insufficient fire or do not hire some workers. Workers who succeed to get a job sign a contract with their new employer for $D$ periods. Firms pay wages. The labor market closes.

2. The consumption goods market opens. Households allocate their total wealth to consumption and savings, visit randomly a given number of firms and from them buy the cheapest goods. Firms collect revenues. The consumption goods market closes.

3. After markets close, all agents update their balance sheets. Firms pay interests and principal to the bank. Firms that cannot validate their debt commitments go bankrupt and are replaced by an equal number of new firms. In case of bankruptcies, the bank registers a bad debt.

\subsection{The labor market}

The actors of the labor market are firms and households. Firms demand labor and offer wages, households supply labor services. Households are constituted by a single worker who offers one unit of labor per period.

\section{Labor demand}

Firm $i$ produces using labor and a technology with constant returns $\alpha$. For simplicity, we assume that technology is uniform across firms and time. Ruling out technological progress implies that our model is best interpreted as a description of the economic activity at business cycles frequencies. 
For a given desired level of production $Y_{i t}^{*}$, labor demand is obtained as

$$
N_{i t}^{d}=\frac{Y_{i t}^{*}}{\alpha}
$$

Then, the firm posts vacancies $V_{i t}$ given by the difference between the desired workforce and the operating workforce $N_{i t-1}$, that is the workers still employed at firm $i$ at the beginning of period $t$.

Because of market imperfections, firm $i$ possesses some degree of market power, which allows it to decide how much to pay its employees. The wage offered by the firm at time $t$ is determined by the following adaptive rule:

$$
w_{i t}= \begin{cases}w_{i t-1}\left(1+\xi_{i t}\right) & \text { if } V_{i t}>0 \\ w_{i t-1} & \text { if } V_{i t} \leq 0\end{cases}
$$

where $w_{i t-1}$ is the wage offered to the workers employed at time $t-1$ and the variable $\xi_{i t}$ is an idiosyncratic shock uniformly distributed on the support $\left(0, h_{\xi}\right)$. Because of labor homogeneity, we assume that at time $t$ all the workers employed by firm $i$ receive the same wage $w_{i t}$. This means that the wage of previously-hired workers is also updated to the new wage.

Through Eq. (4) we basically incorporate into the model the abundant empirical evidence on the downward rigidity of nominal wages. Numerous surveys have shown in fact that even during recessions firms prefer layoffs to wage cuts, mainly because the latter could increase workers' turnover and decrease labor effort from remaining workers (Campbell and Kamlani, 1997; Bewley, 1999; Daly et al., 2013).

\section{Labor supply}

For simplicity we suppose that only unemployed workers search for a new job. Job search takes three steps. First, one by one each unemployed worker $j$ enters the labor market in random order, and contacts a fixed number $M$ of firms sending as many applications. If his/her contract has just expired, one of the applications is sent to his/her last employer. Parameter $M$, therefore, tunes labor market frictions due to search costs. Second, once the $M$ contacted firms have revealed their wage offers, those paying wages below worker $j$ 's reservation wage are discarded. The worker's reservation wage is given by

$$
w_{j t}^{r}= \begin{cases}w_{j t-1} & \text { if employed in } t-1 \\ w_{j t-1}^{r}\left(1-\chi_{j t}\right) & \text { if unemployed in } t-1,\end{cases}
$$

where $\chi_{j t}$ is a random shock uniformly distributed on the support $\left(0, h_{\chi}\right)$. Eq. (5) therefore implies that workers who have experienced longer spells of unemployment will have in general lower reservation wages and will be more prone to accepting lower wages. Finally, the applicant worker chooses, among the remaining firms that still have open vacancies, the one offering the highest salary. The newly employed worker and the firm sign a fixed-term job contract lasting $D$ periods.

Workers with an active contract can be fired only in case the firm's funds are not sufficient to pay for the wage bill. If this is not the case, therefore, on average every period a share $1 / D$ 
of job contracts expires, and the newly-unemployed workers will search for a new employer. Consequently, although on-the-job search is ruled out, the reciprocal of the contract duration $D$ can be interpreted as the probability for a worker to change job.

\subsection{The credit market}

Firms and bank participate to the credit market.

\section{Credit demand}

After the closure of the labor market firm $i$ needs to pay a wage bill $W_{i t}$. At the beginning of period $t$ firm $i$ is endowed with liquid resources $D_{i t}$, i.e. its bank deposits. Following the "pecking order" theory on business capital structure (e.g. Myers and Majluf, 1984), we assume the wage bill to be first financed by internal resources and then, if these are not enough, by external funds provided by the bank. The demand for new bank loans is therefore given by

$$
B_{i t}^{d}=\max \left(W_{i t}-D_{i t}, 0\right),
$$

with the corresponding interest rate $r_{i t}$ given by Eq. (8).

As we explain in detail below, the firm may be rationed by the bank if its credit rating $C R_{i t}$ is too low. As a consequence, the amount of new credit $B_{i t}$ actually supplied by the bank may be lower than credit demand. In this case, total financial resources are not sufficient to pay for the wage bill, and the firm is allowed to fire redundant workers at zero costs.

\section{Credit supply}

The bank acts as a reduced-form financial system and has three functions: it is the center of the payment system, supplies credit to firms and pays interests on households' deposits.

If a firm experiences a shortage of financial resources to pay wages, it will ask for a bank loan $B_{i t}^{d}$ (see Eq. (6)). The bank signs with firm $i$ a long-term debt contract, stating the interest rate $r_{i t}$ and the share $\tau$ of the principal to be repaid every period. For simplicity we suppose that the share $\tau$ is the same for every borrower.

The flow of new credit $B_{i t}$ is granted by the bank to firm $i$ according to the following adaptive rule:

$$
B_{i t}= \begin{cases}B_{i t}^{d} & \text { if } C R_{i t}>\theta \\ 0 & \text { if } C R_{i t} \leq \theta\end{cases}
$$

where $C R_{i t}$ is the firm's credit rating and $\theta$ is the parameter which regulates the bank's lending attitude. The higher the parameter $\theta$, therefore, more frequently credit rationing will occur.

The firm's credit rating at time $t$ is defined as 1 minus its probability of default. To keep things simple, we suppose that the bank computes the probability of bankruptcy simply as the firm's relative frequency of default over the window of the last $\Phi$ periods, where $\Phi$ is a parameter. For example, if the firm has defaulted twice during the periods $t-\Phi, \ldots, t-1$, we have $C R_{i t}=$ 
$(\Phi-2) / \Phi$. Hence, the bank will resume lending to firm $i$ only if the latter's credit rating increases above the threshold $\theta$.

The interest rate $r_{i t}$ is determined as a mark-up over the policy rate $i_{t}$ set by the central bank:

$$
r_{i t}=i_{t}\left(1+\mu\left(\lambda_{i t}\right)\right) .
$$

The mark-up in turn is an increasing function $\mu(\cdot)$ of the borrower's leverage $\lambda_{i t}$. Function $\mu(\cdot)$ is the hyperbolic tangent, ${ }^{2}$ whereas the firm's leverage is simply defined as

$$
\lambda_{i t}=\frac{L_{i t}+B_{i t}^{d}}{D_{i t}} .
$$

Equation (8) is based on the "external finance premium" theory (Bernanke and Gertler, 1989; 1990), stating that in presence of asymmetric information the interest rate increases with the borrower's financial fragility (here straightforwardly captured by the leverage $\lambda_{i t}$ ).

Finally, the bank pays out interests on households' deposits at the current policy rate $i_{t}$.

\subsection{The consumption goods market}

The players on the consumption goods market are firms (supply) and households (demand).

\section{Goods supply}

Firms produce the same homogeneous consumption good but, because of imperfect competition caused by uncertainty and consumer search costs, they have some degree of market power. Firm $i$ 's strategy at the beginning of each period $t$ is therefore the couple $\left(P_{i t}, Y_{i t}^{*}\right)$, where $P_{i t}$ is the price and $Y_{i t}^{*}$ is the desired production level. We suppose that firm $i$ can adjust either the price or the desired production level, but not both. The assumption of ruling out simultaneous changes of price and quantity is a rather strong simplification, which nonetheless can be justified on the basis of the empirical evidence on price and quantity adjustment of firms over the business cycle (Kawasaki et al., 1982; Bhaskar et al., 1993).

Firms' knowledge of market conditions is always imperfect because of uncertainty and, consequently, they need to form expectations $D_{i t}^{e}$ on current demand. We assume that the goods are perishable, which means that firms cannot take inventories to the next period to satisfy future demand. We can therefore think of our model as a representation of a modern service-based economy. As a consequence, the desired quantity of goods to supply $Y_{i t}^{*}$ is always set at the level of expected demand $D_{i t}^{e}$. However, actual production $Y_{i t}$ may differ from the desired level $Y_{i t}^{*}$ if firms are constrained on the credit market and/or on the labor market.

The relevant information at time $t$ for firm $i$ to choose its strategy consists of the average market price $P_{t-1}$ and of the individual excess demand/supply recorded in the previous period and captured by unsold inventories $I_{i t-1}$. Although goods cannot be stored, inventories are used by firms as market signals: if inventories are positive, the firm argues that demand for its good has been overestimated, otherwise the firm infers that demand has been underestimated or exactly estimated.

2 The hyperbolic tangent function is defined $\operatorname{as} \tanh (x)=\frac{e^{x}-e^{-x}}{e^{x}+e^{-x}}$, with $\tanh (+\infty)=1, \tanh (-\infty)=-1 \operatorname{and} \tanh (0)=0$. 
As above explained, firms adjust either the price or the quantity, which means that when one of the two is changed the other one remains equal to its current value. The price is adjusted according to the following adaptive rule:

$$
P_{i t}=\left\{\begin{array}{lll}
P_{i t-1}\left(1+\eta_{i t}\right) & \text { if } I_{i t-1}=0 \text { and } P_{i t-1}<P_{t-1} \\
P_{i t-1}\left(1-\eta_{i t}\right) & \text { if } I_{i t-1}>0 \text { and } P_{i t-1} \geq P_{t-1}
\end{array}\right.
$$

where $\eta_{i t}$ is an idiosyncratic random variable uniformly distributed on the support $\left(0, h_{\eta}\right)$. The logic of this rule is that excess demand $\left(I_{i t-1}=0\right)$ is conducive to upwards price revisions only when the firm is competitive (price below the average market price). In this case the firm can raise the price in order to widen its profit margins. Conversely, positive inventories lead to a downward revision of price only if this is above the market price. At any rate, price $P_{i t}$ will never be set below the firm's average costs.

Desired production is determined as follows:

$$
Y_{i t}^{*}=\left\{\begin{array}{lll}
Y_{i t-1}\left(1+\rho_{i t}\right) & \text { if } I_{i t-1}=0 \text { and } P_{i t-1} \geq P_{t-1} \\
Y_{i t-1}\left(1-\rho_{i t}\right) & \text { if } I_{i t-1}>0 \text { and } P_{i t-1}<P_{t-1}
\end{array}\right.
$$

where $\rho_{i t}$ is an idiosyncratic shock uniformly distributed on the support $\left(0, h_{\rho}\right)$. The rationale behind this rule is that positive inventories (excess supply) trigger downwards quantity revisions only when the price is already low enough (below the average market price). In this case the firm does not want to further decrease the price to avoid a deterioration of its profit margins.

\section{Goods demand}

Before the consumption goods market opens, households receive their wage from the firms (if employed) and the interests $i_{t} D_{j t}$ from the bank. Hence, individual income (labor income plus capital income) at time $t$ is defined as:

$$
I_{j t}= \begin{cases}i_{t} D_{j t}+w_{j t} & \text { if } j \text { is an employed worker } \\ i_{t} D_{j t} & \text { if } j \text { is an unemployed worker }\end{cases}
$$

where $D_{j t}$ are household $j$ 's deposits at the beginning of period $t$. Given available financial resources $D_{j t}+I_{j t}$, the consumer allocates a share $c \leq 1$ to consumption and the remaining part to savings. The consumption budget is therefore defined as

$$
C_{j t}=c\left(D_{j t}+I_{j t}\right)
$$

For simplicity we suppose the share $c$ (i.e. the marginal propensity to consume out of wealth) to be the same for all households.

Consumers randomly enter the goods market and, because of search costs, can visit only a fixed number $Z$ of firms, one of them being the largest (in terms of production) firm visited in the previous period. Consumers are assumed to adopt this "preferential attachment" mechanism in order to minimize the probability to be rationed. 
Each consumer attempts to spend his/her consumption budget starting to buy from the firm charging the lowest price among the selected firms. If goods available at the first firm are not enough, the consumer will turn to the second cheapest firm, and so on. Because of uncertainty, therefore, households may not be able to purchase all the desired quantity of goods.

\subsection{Accounting, bankruptcy and replacement}

Upon the closure of the consumption goods market agents update their balance sheets.

\section{Firms}

At the end of period $t$ firm $i$ has sold quantity $Q_{i t} \leq Y_{i t}$ at price $P_{i t}$, collecting revenues $R_{i t}=Q_{i t} P_{i t}$. Firm's profits $\pi_{i t}$ are equal to revenues minus costs, which are the sum of wage bill and loan interests:

$$
\pi_{i t}=R_{i t}-W_{i t}-r_{i t} L_{i t} .
$$

Hence, net worth $E_{i t}$ will evolve according to the law

$$
E_{i t+1}=E_{i t}+\pi_{i t} .
$$

At the end of each period, the firm has also to pay back a fraction $\tau$ of its outstanding debt, which therefore evolves in the following way:

$$
L_{i t+1}=(1-\tau) L_{i t}+B_{i t} .
$$

In principle, above proportional repayment scheme imposes a higher burden on the first time steps after a firm has borrowed money. However, this bias is mitigated by the fact that firms generally ask for loans several times to finance production. Hence, not necessarily the average per-period repayment decreases monotonically over time.

The total cash flow generated by all the transactions occurred during period $t$ is

$$
C F_{i t}=R_{i t}+B_{i t}-W_{i t}-\left(r_{i t}+\tau\right) L_{i t}
$$

whereby we get the law of motion of the firm's liquid resources, i.e. bank deposits:

$$
D_{i t+1}=D_{i t}+C F_{i t} .
$$

We assume that the firm is declared insolvent only if it is not able to serve its debt to the bank, in which case it exits the market. This implies that the firm may remain active even if it is "technically" in default, that is if $E_{i t+1}<0$, provided that deposits $D_{i t+1}$ are positive. When the firm defaults, its employed workers get fired.

The bankrupt firm is replaced by a new one, whose initial capital is financed by the Government through a flat tax $\psi$ levied on households' wealth. This mechanism, although not very realistic, assures stock-flow consistency without affecting wealth inequality and, at the same time, determines a negative impact on the economy by reducing households' spending capacity, as real bankruptcies actually do. 
Price $P_{i t+1}$ and wage $w_{i t+1}$ of the new firm are set to the level of their corresponding average market values $P_{t}$ and $w_{t}$. Moreover, the new firm inherits from the defaulted one a share $\kappa$ of its outstanding debts $L_{i t}$, whereas the remaining part $(1-\kappa)$ is absorbed by the bank's capital as bad debt. We opted for a partial inheritance of debts because in reality there are many ways to manage bankruptcies. For example, the bank may simply accept to reschedule the loan, or the firm shuts down and the bank suffers the complete loss of its credit, in other cases a new firm acquires the defaulted one and takes on all or a part of its debt. Hence, our modeling choice allows to choose the bank's attitude toward defaulted firms simply by tuning parameter $\kappa$. Under this view, the replacement can be interpreted not only as a true substitution of an old firm with a new one, but also as a mere financial restructuring of the same defaulting firm.

The perfect replacement of bankrupt firms, used to keep constant the number of firms, can be motivated on the basis of two widely accepted stylized facts: first, in established industries the number of firms tend to settle down around a roughly constant level (Sutton, 1997); second, the inflows and outflows of firms show strong positive correlation (Geroski, 1991, reports a correlation coefficient of 0.796 for a sample of 95 industries in United Kingdom in 1987). So, in the model we are implicitly assuming a correlation equal to 1 . We can therefore imagine that our model describes the behavior of a "mature" and stable economy characterized by little innovation. Moreover, a constant population may also be interpreted as a statistical equilibrium, where at the micro level firms continuously enter and exit the market but at the macro level the population remains rather stable.

\section{Households}

At the end of time $t$ household $j$ 's wealth is totally held in bank deposits, which evolve according to the following:

$$
D_{j t+1}=D_{j t}+I_{j t}-C_{j t}-\Psi_{j}
$$

where $I_{j t}$ is given by Eq. (12), $C_{j t}$ is the expenditure on consumption and $\Psi_{j}$ is the household's total contribution to help the Government to refinance defaulted firms (see above section 2.5).

\section{The bank}

At the end of the period the bank calculates its profits:

$$
\pi_{t}^{b}=\sum_{i \in \Omega} r_{i t} L_{i t+1}-\sum_{j=1}^{H} I n t_{j t}-B D_{t}
$$

where $\Omega$ is the bank's loan portfolio, $I n t_{j t}=i_{t} D_{j t}$ are the interests paid on household $j$ 's deposits at the beginning of period $t$ and $B D_{t}$ is the bank's bad debt (non-performing loans) recorded at the end of the period. As explained in Section 2.5, bad debt is defined as a fraction $(1-\kappa)$ of bankrupt firms' outstanding debts.

Total bank credit evolves according to the following law of motion:

$$
L_{t+1}=(1-\tau) L_{t}+\sum_{i \in \Theta} B_{i t}-B D_{t},
$$


where $\Theta$ is the set of firms that borrowed in period $t$.

Finally, the law of motion for the bank's equity can be defined as

$$
E_{t+1}=E_{t}+\pi_{t}^{b} \equiv L_{t+1}-D_{t+1}
$$

\subsection{Results}

In this Section we present a brief overview of some general properties of the model, discarding the first 100 periods. ${ }^{3}$ Fig. 1 shows four time series relative to a typical simulation, obtained using the parameter values reported in Table 3. These baseline parameters will be changed in Section 3 when performing sensitivity analysis.

Panel 1(a) shows real GDP, while the closely related unemployment rate is reported in Panel 1(b). We can see that the economic activity is characterized by a rather regular alternation of expansions and recessions without a tendency to converge to some steady-state. This cyclical behavior cannot be explained in terms of microeconomic frictions such as search costs (which are fixed) or exogenous aggregate shocks (which are not), but is caused by a combination of idiosyncratic random shocks and non-linear relationships. A major driving force behind fluctuations is firms' cash flow. During expansions, in fact, unemployment drops, wages rise and firms build up debts to finance increasing production. As long as revenues are sufficient for firms to pay interests on their bank loans, production can continue to expand. However, debt accumulation and rising

Table 3: Parameters.

\begin{tabular}{lll}
\hline Parameter & Description & Value \\
\hline$T$ & Number of periods & 500 \\
$F$ & Number of firms & 100 \\
$H$ & Number of workers & 600 \\
$Z$ & Number of firms visited by a consumer & 4 \\
$M$ & Number of labor applications & 4 \\
$D$ & Job contract length & 8 \\
$c$ & Marginal propensity to consume & 0.8 \\
$h_{\eta}$ & Maximum growth rate of prices & 0.1 \\
$h_{\rho}$ & Maximum growth rate of quantities & 0.1 \\
$h_{\xi}$ & Maximum growth rate of wages & 0.05 \\
$h_{\chi}$ & Maximum \% decrease of reservation wages & 0.05 \\
$\psi$ & Recapitalization coefficient & 0.01 \\
$i_{t}$ & Policy rate & 0.01 \\
$\theta$ & Credit rating threshold & 0.2 \\
$\tau$ & Debt repayment rate & 0.05 \\
$\Phi$ & Defaulting window & 10 \\
$1-\kappa$ & Share of bad debt & 0.05 \\
\hline
\end{tabular}

3 The model was implemented in MATLAB, and the code is available upon request. 


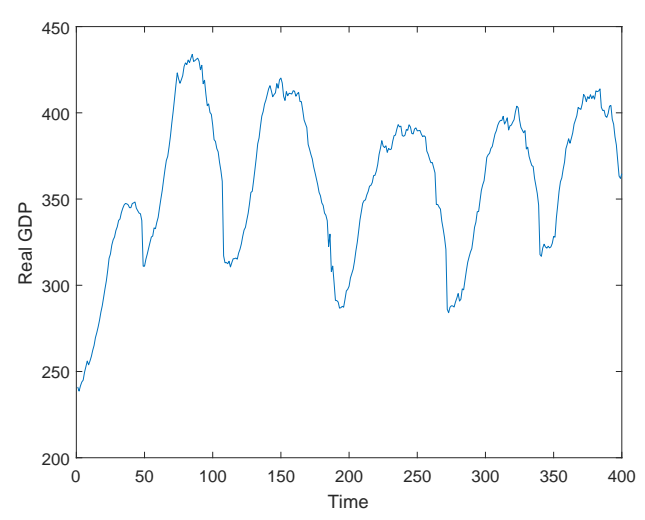

(a)

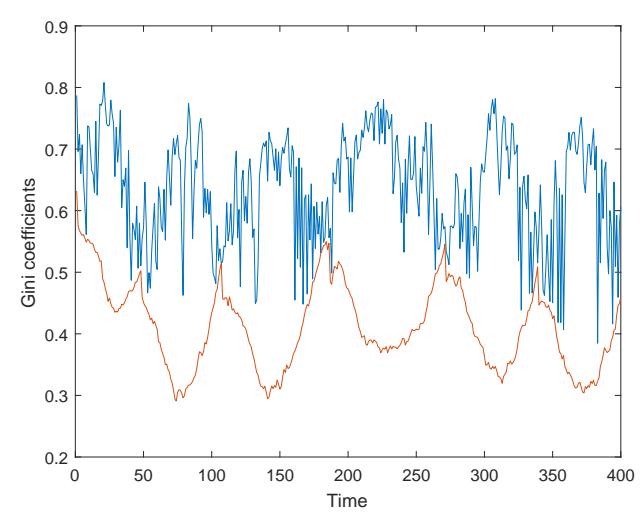

(c)

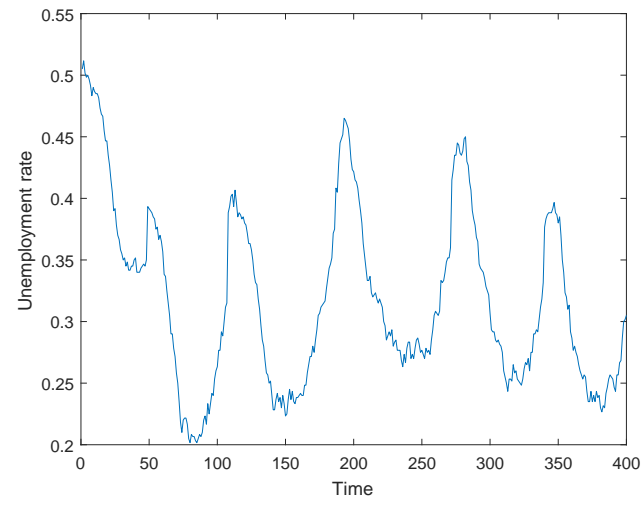

(b)

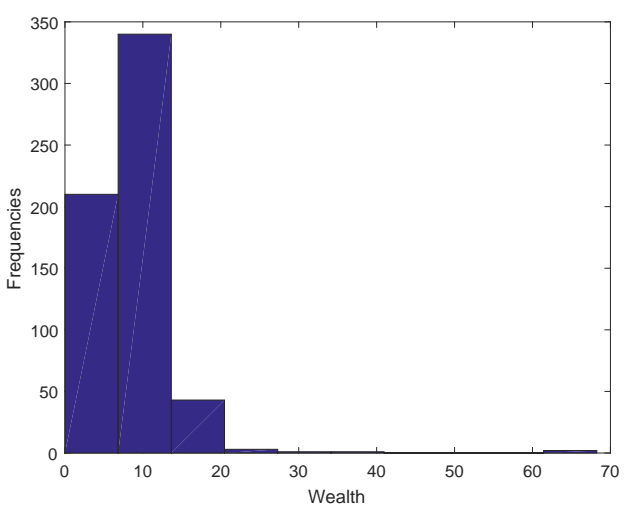

(d)

Figure 1: (a): Real output; (b): Unemployment rate; (c): Gini coefficients for wealth (blue line) and income (red line); (d): Wealth distribution at $t=500$.

labor and financial costs reduce firms' cash flow and, eventually, may lead to bankruptcy. If the number of bankrupted firms is large enough, or if big firms default, aggregate production shrinks and unemployment increases. The loss of jobs determines a reduction in households' income and consumption, which in turn negatively affects firms' sales and profits. Moreover, a second-order 'financial accelerator' mechanism adds to the ongoing recession, because bankruptcies, by lowering firms' credit worthiness, lead to credit rationing by the bank (Eq. 7). However, recessions have also the important function of wiping less efficient and more indebted firms out of the market. This natural selection mechanism in the long run helps to make the economy financially sounder and, eventually, leads to a new expansion phase.

Strictly speaking, the levels of unemployment displayed by the model in the baseline simulation (between 20\% and 45\%) are difficult to see in modern, developed Countries. Nonetheless, we should take into consideration that the model does not feature a public sector. Government expenditure, in facts, is the main stabilizer of modern economies together with active monetary policy, and in our model we have neither of the two. In addition, the model is not calibrated, that 
is the baseline parameter configuration was not chosen to make the simulated data close to the real ones. As a consequence, absolute values (i.e. first moments) should not be given too much importance whereas, on the contrary, relative values such as co-movements should be considered. A co-movement analysis, in fact, reveals that the model is rather realistic at business-cycle frequencies, as the cyclical components of GDP, unemployment, consumption and inflation display cross-correlations that are very similar to the empirical counterparts of U.S. economy at quarterly frequencies (for more details we refer to Chen and Desiderio, 2018).

At a lower level of aggregation the model reproduces qualitatively several empirical regularities concerning job flows. We find in fact that unemployment is positively correlated to long-term unemployment (defined as the workforce that has been unemployed for more than three periods), that layoffs and hirings are strongly correlated both in levels and in differences, and that layoffs show higher volatility and are more correlated to unemployment than hirings (Blanchard and Diamond, 1990; Davis et al., 1996). Moreover, the model also replicates three well-known statistical regularities describing the interplay between labor market and aggregate activity at business cycles frequencies, namely the Phillips curve, the Beveridge curve and the Okun law.

As all in all our model displays quite realistic features, we deem it as a valid tool to perform computational experiments. Thus, in the next section we will use it to study the relationship between job contract duration and inequality.

\section{Computational experiments}

In this Section we will assess the effect of job contract duration on income and wealth inequality, measured by the Gini index. We start by a local sensitivity analysis exercise (Section 3.1) involving parameter $D$, then in Section 3.2 we will check the robustness of our result by a global sensitivity analysis, that is by controlling for other relevant model parameters. Finally, in Section 3.3 we will examine possible non-linearities and interactions with other parameters through a pairwise sensitivity analysis.

\subsection{Local sensitivity analysis}

In this Section we analyze the behavior of inequality for increasing values of the job contract length $D$, going from 1 to 16 . For each value of contract duration we run 100 independent simulations of 500 periods; for each simulation $i$ we compute the average Gini coefficient $g_{i}$ relative to the variables of interest discarding the first 100 transient periods and then we take the Monte Carlo average $\bar{g}=100^{-1} \sum_{i} g_{i}$ across simulations.

Figure 2 shows the results. ${ }^{4}$ In Panel (a) we can see the average Gini index for wealth decreasing monotonically. As for income, from Panel (b) we can see that the relationship is less clear, with the Gini index first increasing and then decreasing monotonically for $D>2$. We also fit the two curves using different regression models of contract duration, involving levels, quadratics and

4 The Gini coefficients are pretty high, but Piketty $(2014,248-249)$ reports a wealth Gini of 0.67 for a medium-high inequality, of 0.73 for a high inequality and 0.85 for a very high inequality, and an income Gini of 0.49 for high inequality and 0.58 for very high inequality. 


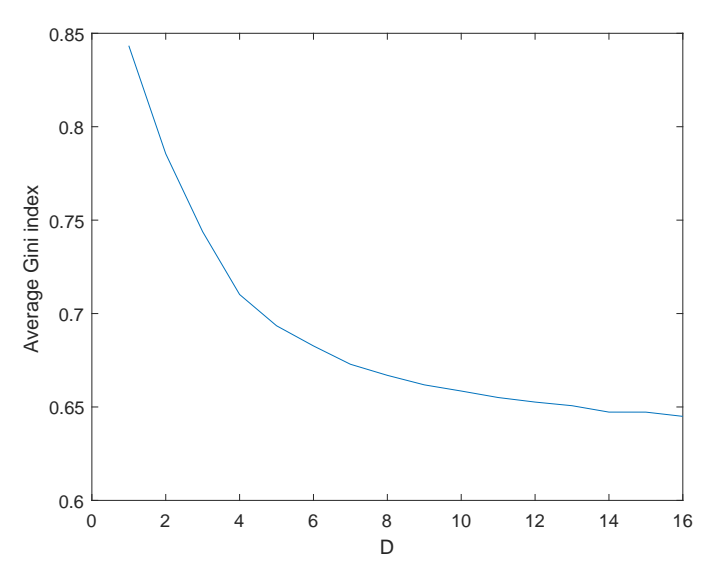

(a)

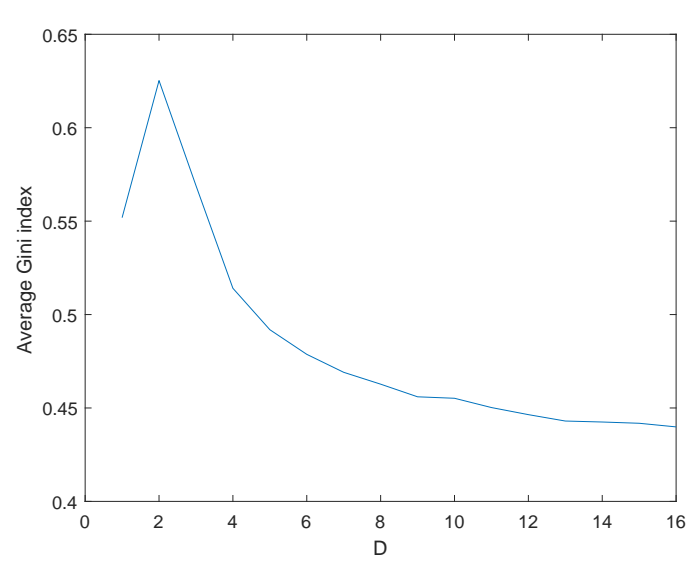

(b)

Figure 2: Monte Carlo Gini index as function of job contract duration for (a): wealth; (b): income.

logarithms. These models are then ranked according to their coefficients of determination. With an $R^{2}$ of about $99 \%$ we rank as the best fit for wealth a model with both the logarithm and the squared logarithm of parameter $D$ (implying a theoretical turning point at about $D=35$ ), while for income the best model includes the level $D$ and the quadratic term $D^{2}\left(R^{2}\right.$ of about $86 \%$ and estimated turning point between 12 and 13). In both cases the estimated models prompt that the relationship between Gini index and job contract duration is decreasing over the considered parameter space, but also that it might be non-monotonic for larger values of $D$.

Different mechanisms link inequality to job contracts. The principal channel through which contracts affect inequality is probably unemployment, because when more workers are employed income distribution becomes less unequal among the poorer classes of the population, that is those who suffer more from the loss of jobs. This is confirmed by Panel (a) of Figure 3, where the Monte Carlo unemployment rate is reported. A glance at this variable, in fact, reveals that its response to parameter $D$ closely follows that of the income Gini index: as $D$ increases, unemployment first increases and then decreases monotonically for $D>2$. The reason why this happens is straightforward: when contracts are longer, in fact, firms can fire workers less frequently and therefore they are forced to pay wages even when this is not economically efficient from the individual point of view. On the other hand, however, this microeconomic inefficiency has the unintended consequence of sustaining aggregate demand for the consumption good. In other words, longer contracts increase the likelihood of having macroeconomic coordination between aggregate demand and supply, thus reducing the probability to experience recessions and long periods of high unemployment. However, we will see that this mechanism works specially when monetary policy and the commercial bank's credit policy are loose.

Another channel through which contracts affect inequality is wage dispersion. Longer contracts, in fact, reduce wage dispersion just as they reduce income inequality. This can be seen in Panel (b) of Figure 3, which shows that the Monte Carlo coefficient of variation of nominal wages behaves very similarly to income inequality. There are basically two reasons for this to happen. 


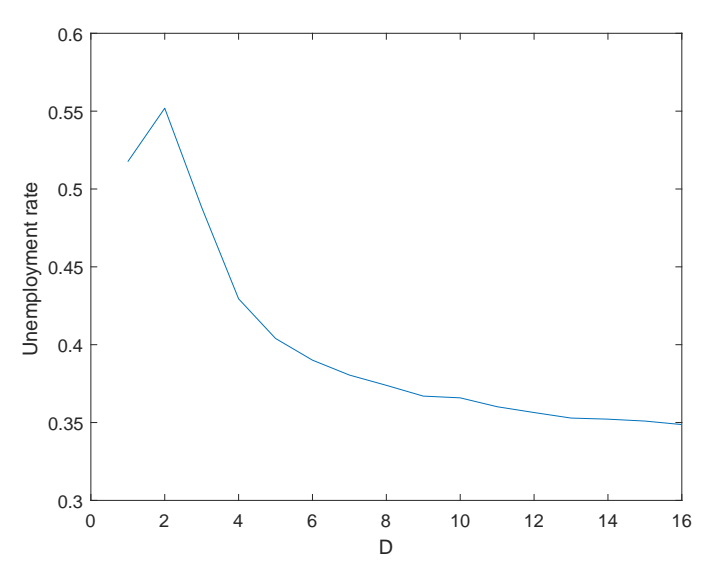

(a)

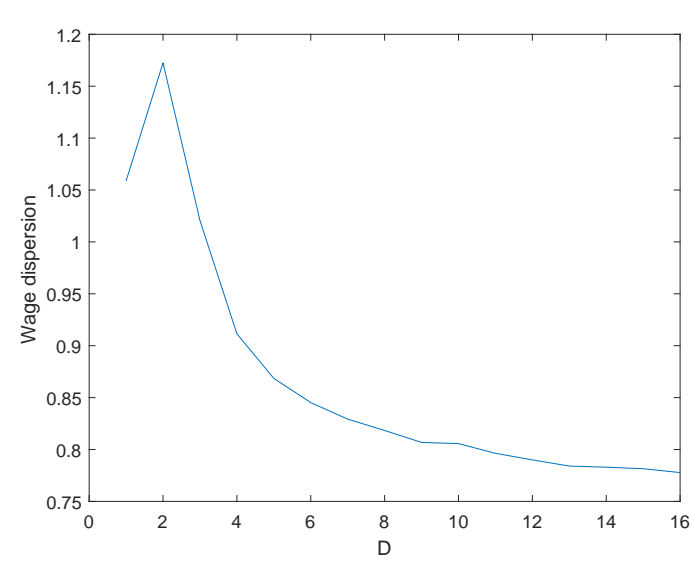

(b)

Figure 3: (a): Monte Carlo unemployment rate; (b): Monte Carlo coefficient of variation of nominal wages.

First reason: if jobs terminate less often, then firms need to open less vacancies and, according to Eq. (4), to raise less frequently their wage offer in order to attract workers. Thus, longer contracts reduce wage competition among firms and, as a consequence, also the dispersion of offered wages. There is also a second reason: if contracts are longer, reallocation of workers among firms occurs less frequently and therefore workers have less chances of finding jobs paying higher salaries. This, on average, will reduce the dispersion of actually paid wages. Taken together, these two mechanisms cause longer contracts to reduce wage dispersion and income inequality.

Income inequality is also tightly connected to wealth inequality. Not only does the former affect the latter through Eq. (19), but the latter positively feeds back into the former as well. Besides wages, in fact, income is also determined by financial revenues (see Eq. (12)), which depend on accumulated wealth. Hence, income inequality is exacerbated by wealth inequality through capital income. Moreover, wealth inequality feeds positively back into itself. Combining Eqs. (12), (13) and (19), in fact, we get the following reduced-form law of motion for wealth:

$$
D_{t+1}=(1-c) w_{t}+(1-c)\left(1+i_{t}\right) D_{t},
$$

proving that inequality is partly cause of itself.

\subsection{Global sensitivity analysis}

The results emerging in Section 3.1 are obtained by changing only the job contract duration $D$, while all the other parameters are fixed at their baseline values. The obvious objection is that the relationship between inequality and contract length may change if the other parameters change. The aim of this Section is therefore to investigate this possibility through a global sensitivity analysis exercise, consisting in changing several parameters simultaneously. To this scope we will use the technique already introduced in Chen and Desiderio (2018), which we briefly illustrate in sub-section The GSA procedure for the reader's sake. Subsequently, we will report our findings in sub-section Results. 


\section{The GSA procedure}

The method is based on the estimation of an auxiliary regression meta-model (Grazzini et al. 2018; Saltelli et al., 2008, ch. 5). Suppose that we want to assess how the model parameters $\gamma$, belonging to the parameter space $\Gamma$, affect a statistic $s$ computed on the output of the agent-based model, which in general will also be a function of initial conditions $A_{0}$ and random numbers $r$ :

$$
s=s\left(A_{0}, \gamma, r\right) .
$$

To do this we resort to the estimation of an auxiliary regression meta-model

$$
s=\beta \gamma+u\left(A_{0}, \gamma, r\right)
$$

where the meta-parameters $\beta$ measure the partial effect of the model parameters $\gamma$ on $s$. In principle, the regression error $u$ may depend on the initial conditions, on the stream of random numbers and on the model parameters. For simplicity, we will assume that the error does not depend on the initial conditions, which is true if the data generating process of the model is ergodic, and on $\gamma$. Assuming that error term $u$ does not depend on $\gamma$ amounts to assume that the relationship between $s$ and the model parameters be indeed linear. If this is not true, model (24) can always be augmented with non-linear functions of $\gamma$. Hence, from now on we will suppose that the error depends only on the stream of random numbers $r$.

In order to estimate the meta-model we have to generate $n$ vectors $\gamma_{i}$ randomly sampled from the parameter space $\Gamma$ and $n$ streams of numbers $r_{i}$. Then, for each vector $\gamma_{i}$ and stream $r_{i}$ we simulate the agent-based model $n$ times, obtaining $n$ values $s_{i}$ for the statistic of interest. ${ }^{5}$ Consequently, using the samples for $s$ and for the parameters we can estimate by OLS the relationship

$$
s_{i}=\beta \gamma_{i}+u\left(r_{i}\right), \forall i=1 \ldots n,
$$

obtaining estimated meta-parameters $\hat{\beta}$. Clearly, these estimates depend on the unobserved sequences of random numbers. However, the central point of our approach is that we treat the numbers $r_{i}$ in Eq. (25) simply as omitted explanatory variables influencing $s_{i}$ through the error term. And as the stream $r_{i}$ was randomly selected, necessarily it is uncorrelated with the regressors $\gamma_{i}$, which therefore are not correlated even with the error $u_{i}$. Hence, under the assumption that the regression model (25) is correctly specified, the OLS estimators $\hat{\beta}$ applied to it are consistent for $\beta$ when $n \rightarrow+\infty$.

The strength of our approach, therefore, is both its simplicity of implementation and its parsimony in terms of required computational effort. ${ }^{6}$

\section{Results}

As already explained, we perform GSA to make sure that the results obtained in Sec. 3.1 are robust to changes to other parameters. In this Section we are going to apply the approach explained

\footnotetext{
5 In practice, when for a given $\gamma_{i}$ we run a simulation of the agent-based model to generate the corresponding $s_{i}$, we randomly choose the seed of the random number generator.

6 We point out that this technique can also be applied to local sensitivity analysis and, therefore, can be conveniently used for fast preliminary explorations of the model features.
} 
Table 4: Parameter space.

\begin{tabular}{lll}
\hline Parameter & N. of values & Range \\
\hline$D$ & 15 & {$[2-16]$} \\
$M$ & 9 & {$[2-10]$} \\
$i_{t}$ & 100 & {$[0.001-0.05]$} \\
$\theta$ & 100 & {$[0.1-0.9]$} \\
$h_{\xi}$ & 100 & {$[0.005-0.2]$} \\
$c$ & 100 & {$[0.1-0.99]$} \\
\hline
\end{tabular}

above to equation (25) controlling for a set of parameters that we deem relevant for inequality. Besides the job contract duration $D$, these are the number of job applications $M$, the policy rate $i_{t}$ (which is actually held fixed within a given simulation), the bank's lending attitude $\theta$, the maximum wage growth rate $h_{\xi}$ (see Eq. (4)) and the marginal propensity to consume $c$. Hence, $\gamma=\left(D, M, i_{t}, \theta, h_{\xi}, c\right)^{\prime}$ and $s$ will be both the income and wealth Gini coefficient.

For each parameter we restrict the corresponding parameter space $\Gamma$ to a suitable range of values, as summarized by Table 4 . From the parameter space we randomly draw 500 parameter vectors $\gamma_{i}$ and run the model 500 times (so, $i=1 \ldots 500$ ), choosing randomly also the seed of the random number generator. Then, for each simulation we take the average Gini coefficients after discarding the first 100 periods.

Table 5 reports the results. Overall, the meta-model explains about the $73 \%$ of the variability of wealth Gini coefficient and about the $70 \%$ of the variability of the income Gini. As we can see, our previous result is confirmed by GSA: longer contract duration decreases inequality, even when other parameters change. Inequality is reduced also when labor market frictions decrease (higher $M$ ), probably because a more efficient matching between demand and supply of labor reduce unemployment (Table 6, column (1)). Conversely, all the other parameters increase inequality, with only slight differences between income and wealth.

Table 5: Global sensitivity analysis.*

\begin{tabular}{lll}
\hline Regressors & $(1)$ & $(2)$ \\
\hline$D$ & $-.0032487^{* * *}$ & $-.0040573^{* * *}$ \\
$M$ & $-.0071622^{* * *}$ & $-.0088425^{* * *}$ \\
$i$ & $2.578706^{* * *}$ & $3.737546^{* * *}$ \\
$\theta$ & $.5541099^{* * *}$ & $.6499673^{* * *}$ \\
$h_{\xi}$ & $1.479424^{* * *}$ & $1.877328^{* * *}$ \\
$c$ & $.4308005^{* * *}$ & $.1739708^{* *}$ \\
constant & $.0775336^{* * *}$ & $.0788892^{* * *}$ \\
\hline$R^{2}$ & 0.7325 & 0.7027 \\
\hline
\end{tabular}

* Dependent variables: (1) wealth Gini index; (2) income Gini index. Observations $=500$. Significant at $1 \%$ : $^{* *}$; at $5 \%:^{* *}$; at $10 \%:^{*}$. 
Table 6: Global sensitivity analysis.*

\begin{tabular}{lll}
\hline Regressors & $(1)$ & $(2)$ \\
\hline$D$ & $-.0071242^{* * *}$ & $-.0394336^{* * *}$ \\
$M$ & $-.0050102^{* *}$ & -.0164015 \\
$i$ & $3.643887^{* * *}$ & $11.57396^{* * *}$ \\
$\theta$ & $.5434112^{* * *}$ & $3.813831^{* * *}$ \\
$h_{\xi}$ & $1.552907^{* * *}$ & $8.93351^{* * *}$ \\
$c$ & $.1597501^{* * *}$ & $.6994892^{* *}$ \\
constant & $.1082692^{* * *}$ & $-1.091638^{* * *}$ \\
\hline$R^{2}$ & 0.6888 & 0.7122 \\
\hline
\end{tabular}

* Dependent variables: (1) unemployment rate; (2) coefficient of variation of nominal wages. Observations $=500$. Significant at $1 \%:^{* * *}$; at $5 \%:^{* *}$; at $10 \%:^{*}$.

Another important application of global sensitivity analysis is that of discovering possible interaction effects among parameters, and our approach is no exception. In order to assess how job contract duration interacts with other mechanisms, in fact, it would be sufficient to augment equation (25) with a series of interaction terms between $D$ and the other parameters, along with non-linear terms. However, because of limited sample variation in the model parameters $\gamma$, in our case multicollinearity turns out to be an issue. So, we devote the next section to the partial solution to this problem.

\subsection{Pairwise sensitivity analysis}

In this Section we are going to assess the interaction effects between contract duration $D$ and the other parameters $\gamma_{-D}=\left(M, i_{t}, \theta, h_{\xi}, c\right)^{\prime}$. To this scope we will apply for five times the same approach to GSA illustrated in Sec. 3.2 but allowing only one parameter at time to vary along with $D$. In addition, besides an interaction term we include also the quadratics in order to control for non-linearities.

Tables 7, 8, 9, 10 and 11 show the results. In general, $D$ appears to interact with other parameters, in particular with the policy rate $i_{t}$ and the bank's lending attitude. In fact, the coefficient on the interaction terms $\left(D \cdot i_{t}\right.$ and $\left.D \cdot \theta\right)$ are both positive and statistically significant. This means that the ability of longer job contracts to curb inequality is reduced in presence of a more restrictive monetary policy (higher $i_{t}$ ) or credit policy (higher $\theta$ ). In principle, one can even figure out a level for $i_{t}$ and $\theta$ such that longer contracts actually increase inequality. To corroborate our claims, in Figure 4 we report both Gini coefficients plotted against parameter $D$ but conditional to different values of the policy rate $i_{t}$ : what we can see is that the relationship is decreasing for $i_{t}<0.02$ and increasing for $i_{t} \geq 0.02$ (the same happens if we condition on different values of parameter $\theta$ ). The explanation is straightforward. As before argued, longer contracts help sustain aggregate demand but, at the same time, place a higher financial burden on firms. So, when monetary policy is loose and/or there is easy access to credit, firms can continue to operate normally by getting 
more into debt, but in the opposite situation high cost of money and reduced availability of credit increase the firms' probability of bankruptcy and, thus, unemployment.

These findings suggest once more how economic mechanisms are closely intertwined. In particular, we can see that microeconomic policies aimed at affecting the rigidity of the labor market may interact with macro policies: more flexible labor markets may decrease inequality and/or foster growth in one macroeconomic framework, but may well have opposite effects in other macro contexts. Thus, neglecting the interconnections operating through different markets and different levels of the economic activity can lead to biased theoretical propositions and consequently to wrong policy-making. This could even explain why earlier and more recent empirical investigations on labor market rigidity have produced rather contrasting results: simply, they referred to very different macroeconomic contexts.

Table 7: Pairwise sensitivity analysis.*

\begin{tabular}{lll}
\hline Regressors & $(1)$ & $(2)$ \\
\hline$D$ & $-.0212296^{* * *}$ & $-.0240443^{* * *}$ \\
$D^{2}$ & $.0008061^{* * *}$ & $.0009428^{* * *}$ \\
$M$ & $-.0408372^{* * *}$ & -.0739105 \\
$M^{2}$ & $.0025112^{* * *}$ & $.0048221^{* * *}$ \\
$D \cdot M$ & $-.0002063^{*}$ & -.0003974 \\
constant & $.8959761^{* * *}$ & $.7982146^{* * *}$ \\
\hline$R^{2}$ & 0.9566 & 0.8709
\end{tabular}

* Dependent variables: (1) wealth Gini index; (2) income Gini index. Observations $=100$. Significant at $1 \%:^{* * *}$; at $5 \%:^{* *}$; at $10 \%:^{*}$.

Table 8: Pairwise sensitivity analysis.*

\begin{tabular}{lll}
\hline Regressors & $(1)$ & $(2)$ \\
\hline$D$ & $-.0252143^{* * *}$ & $-.0242421^{* * *}$ \\
$D^{2}$ & $.0005836^{* *}$ & .0000874 \\
$i$ & $-8.352666^{* * *}$ & $-10.4918^{* * *}$ \\
$i^{2}$ & $128.7976^{* * *}$ & $143.2883^{* * *}$ \\
$D \cdot i$ & $.5299984^{*}$ & $.9531615^{* * *}$ \\
constant & $.8429809^{* * *}$ & $.6739915^{* * *}$ \\
\hline$R^{2}$ & 0.6530 & 0.6585
\end{tabular}

* Dependent variables: (1) wealth Gini index; (2) income Gini index. Observations $=100$. Significant at $1 \%$ :**; $^{* *}$ $5 \%$ :** $^{*}$ at $10 \%$ :* $^{*}$ 
Table 9: Pairwise sensitivity analysis.*

\begin{tabular}{lll}
\hline Regressors & $(1)$ & $(2)$ \\
\hline$D$ & $-.0303895^{* * *}$ & $-.0511326^{* * *}$ \\
$D^{2}$ & $.0009897^{* * *}$ & $.0019148^{* * *}$ \\
$\theta$ & $-.6169521^{* * *}$ & $-1.010256^{* * *}$ \\
$\theta^{2}$ & $.9640496^{* * *}$ & $1.585148^{* * *}$ \\
$D \cdot \theta$ & $.0135256^{* * *}$ & $.0169756^{* *}$ \\
constant & $.874455^{* * *}$ & $.8030813^{* * *}$ \\
\hline$R^{2}$ & 0.9275 & 0.9158
\end{tabular}

* Dependent variables: (1) wealth Gini index; (2) income Gini index. Observations $=100$. Significant at $1 \%$ : $^{* *}$; at $5 \%$ :** $^{*}$ at $10 \%:^{*}$.

Table 10: Pairwise sensitivity analysis.*

\begin{tabular}{lll}
\hline Regressors & $(1)$ & $(2)$ \\
\hline$D$ & $-.0136754^{* * *}$ & $-.0169911^{*}$ \\
$D^{2}$ & $.0005007^{* *}$ & $.0007818^{* *}$ \\
$h_{\xi}$ & $1.601388^{* * *}$ & $2.639591^{* * *}$ \\
$h_{\xi}^{2}$ & $-2.854801^{*}$ & -2.539246 \\
$D \cdot h_{\xi}$ & -.027055 & $-.073807^{* *}$ \\
constant & $.6470349^{* * *}$ & $.4035157^{* * *}$ \\
\hline$R^{2}$ & 0.6523 & 0.6263 \\
\hline
\end{tabular}

* Dependent variables: (1) wealth Gini index; (2) income Gini index. Observations $=100$. Significant at $1 \%$ : $^{* * *}$; at $5 \%$ :** $^{*}$ at $10 \%$ : $^{*}$.

Table 11: Pairwise sensitivity analysis.*

\begin{tabular}{lll}
\hline Regressors & $(1)$ & $(2)$ \\
\hline$D$ & $-.0253802^{* * *}$ & $-.04131^{* * *}$ \\
$D^{2}$ & $.001139^{* * *}$ & $.0017461^{* * *}$ \\
$c$ & .0320147 & $.2068659^{* * *}$ \\
$c^{2}$ & $.5478875^{* * *}$ & $-.1262083^{* *}$ \\
$D \cdot c$ & -.0049221 & -.0019306 \\
constant & $.4590701^{* * *}$ & $.5695174^{* * *}$ \\
\hline$R^{2}$ & 0.9440 & 0.7854 \\
\hline
\end{tabular}

* Dependent variables: (1) wealth Gini index; (2) income Gini index. Observations $=100$. Significant at $1 \%:^{* * *}$; at $5 \%:^{* *}$; at $10 \%:^{*}$. 


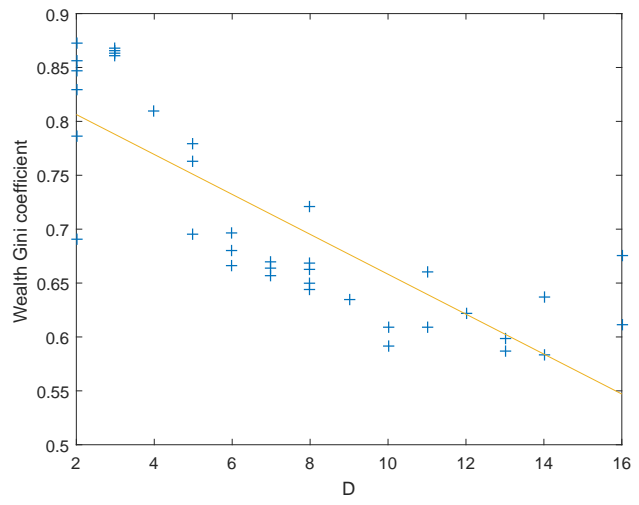

(a)

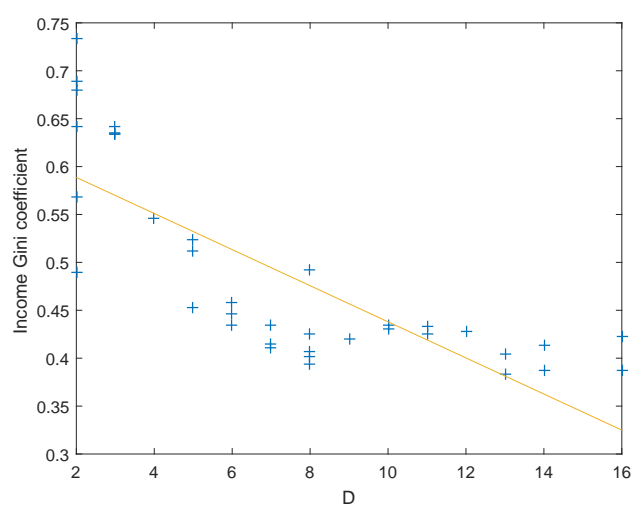

(c)

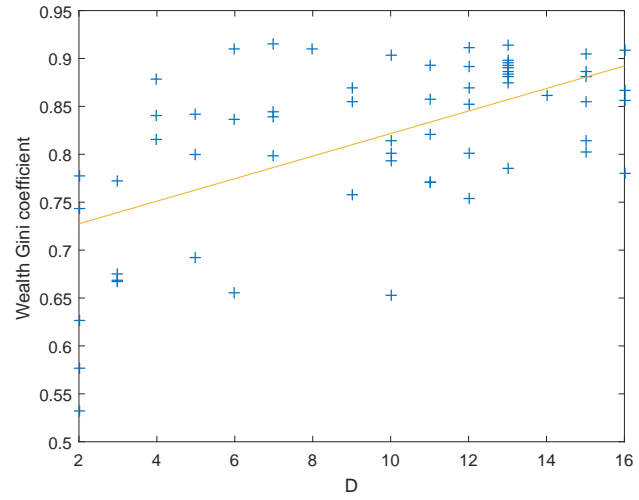

(b)

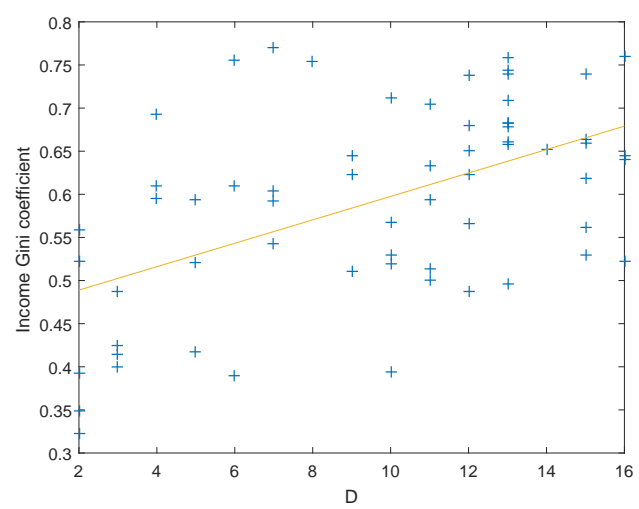

(d)

Figure 4: Scatter plot of $D$ and wealth Gini conditional to: (a) $i_{t}<0.02$; (b) $i_{t} \geq 0.02$. Scatter plot of $D$ and income Gini conditional to: (c) $i_{t}<0.02$; (d) $i_{t} \geq 0.02$.

\section{Conclusive remarks}

Structural labor market reforms have been on the political agenda of many OECD Countries for more than two decades. In particular, these have been aimed at increasing the degree of flexibility of the employer/employee relationship, in the presumption of fostering growth and decreasing unemployment. However, recent empirical evidence has shown that flexibility may have detrimental effects on unemployment and social welfare.

The main concern of this paper is how a major source of flexibility like temporary job contracts affects income and wealth inequality. To this scope we use an agent-based macroeconomic model already presented in Chen and Desiderio (2018), which is quite effective at replicating a number of stylized facts.

By using the model as a computational laboratory, we assess the impact of different job contract durations on inequality through three kinds of sensitivity analysis. The first experiment is a canonical local sensitivity analysis involving contract duration only. The second experiment, involving several parameters at the same time, is carried out as a robustness check. Finally, we 
propose a pairwise sensitivity analysis performed by changing two parameters at time. This experiment is aimed at discovering possible interaction effects between contract duration and other factors. We want to stress that the last two kinds of analysis are implemented through a methodology first introduced by Chen and Desiderio (2018) that reduces the computational burden of simulations.

In line with recent empirical evidence, the three experiments clearly indicate that longer contract length decreases inequality. There are mainly two reasons behind our result. One is that longer contracts reduce the ability of firms to fire workers and therefore force them to pay wages even when this is not economically convenient for the individual firm. This has the macroeconomic consequence of sustaining aggregate demand during downturns, thus reducing unemployment. The second reason is that longer contracts reduce wage competition among firms and, consequently, wage dispersion.

We also find that the positive effects of longer contracts on inequality are diminished by tighter monetary policy and credit policy. The last result might be of particular interest for policy makers, as it prompts that the final effect of institutional reforms may depend also on the macroeconomic context.

Admittedly, our findings could be biased in favor of longer contract duration because of the absence of international linkages. In fact, an economy with a rigid labor market is likely to suffer from the international competition exerted by another economy with more flexible working relationship. Hence, considering open economies as an additional robustness check will be the object of future research.

Acknowledgements We would like to thank two anonymous referees for their valuable suggestions and all the participants to IWcee19, Rome, July 2019. We also gratefully acknowledge the financial support provided by the Natural Science Foundation of Guangdong Province under Grant No. 2018A030310148.

\section{References}

Atkinson, A., (2015). Inequality. What can be done? Cambridge, MA, Harvard University Press.

Atkinson, J., (1985). Flexibility, uncertainty and manpower management. Brighton: Institute of Manpower Studies, University of Sussex.

Autor, D. H., Katz, L. F., Kearney, M. S., (2008). Trends in US wage inequality: Revising the revisionists. The Review of Economics and Statistics, 90(2), 300-323. http://www.mitpressjournals.org/doi/pdf/10.1162/rest.90.2.300

Bernanke, B., Gertler, M., (1989). Financial fragility and economic performance. Quarterly Journal of Economics, 105, 87-114. http://www.jstor.org/stable/2937820

Bernanke, B., Gertler, M., (1990). Agency costs, net worth, and business fluctuations. American Economic Review, 79, 14-31. http://www.jstor.org/stable/1804770

Bewley, T., (1999). Why wages don't fall during a recession. Cambridge, Harvard University Press.

Bhaskar, V., Machin, S., Reid, G., (1993). Price and quantity adjustment over the business cycle: evidence from survey data. Oxford Economic Paper 45, 257-268. http://www.jstor.org/stable/2663638

Blanchard, O. and Diamond, P., (1990). The cyclical behavior of the gross flows of U.S. workers. Brookings Papers on Economic Activity, 2, 85-143. http://www.jstor.org/stable/2534505 
Brancaccio, E., Garbellini, N., Giammetti, R., (2018). Structural labour market reforms, GDP growth and the functional distribution of income. Structural Change and Economic Dynamics, 44, 34-45.

https://doi.org/10.1016/j.strueco.2017.09.001

Cahuc, P., Postel-Vinay, F., (2002). Temporary jobs, employment protection and labor market performance. Labour Economics, 9, 63-91.

Caiani, A., Godin, A., Caversazi, E., Gallegati, M., Kinsella, S., Stiglitz, J. E., (2016). Agent based-stock flow consistent macroeconomics: towards a benchmark model. Journal of Economic Dynamics and Control, 69, 375-408. https://www.sciencedirect.com/science/article/pii/S0165188915301020

Campbell, C., Kamlani, K., (1997). The reasons for wage rigidity: evidence from a survey of firms. Quarterly Journal of Economics, 112, 759-789. http://www.jstor.org/stable/2951255

Carpenter, S. B., Rodgers, W. M., (2004). The disparate labor market impacts of monetary policy. Journal of Policy Analysis and Management, 23(4), 813-830.

Chen, S., Desiderio, S., (2018). Computational evidence on the distributive properties of monetary policy. Economics: The Open-Access, Open-Assessment E-Journal, 12(2018-62), 1-32. http://dx.doi.org/10.5018/economics-ejournal.ja.2018-62

Cincotti, S., Raberto, M., Teglio, A., (2010). Credit money and macroeconomic instability in the agent-based model and simulator eurace. Economics: The Open-Access, Open-Assessment E-Journal, 4(2010-26), 1-32. http://dx.doi.org/10.5018/economics-ejournal.ja.2010-26

Daly, M. C., Hobijn, B., Ni, T., (2013). The path of wage growth and unemployment. Federal Reserve Bank of San Francisco Economic Letter, July 15.

https://www.frbsf.org/economic-research/publications/economic-letter/2013/july/wages-unemployment-rate/

Davis, S., Haltiwanger, J., Schuh, S., (1996). Job creation and destruction. MIT Press, Cambridge, MA.

Delli Gatti, D., Desiderio, S., (2015). Monetary policy experiments in an agent-based model with financial frictions. Journal of Economic Interaction and Coordination, 10(2), 265-286.

https://link.springer.com/article/10.1007/s11403-014-0123-7

Desiderio, S., Chen, S., (2016). Why the rich become richer: insights from an agent-based model. International Journal of Computational Economics and Econometrics, 6, 258-275. http://www.inderscience.com/link.php?id=77249

Desiderio, S., Delli Gatti, D., Gallegati, M., (2015). The dynamics of the labour market in an agent-based model with financial constraints. In Cristini A., Fazzari S., Greenberg E., Leoni R., (Eds.), Cycles, Growth and the Great Recession. Routledge.

Dosi, G., Fagiolo, G., Napoletano, M., Roventini, A., (2013). Income distribution, credit and fiscal policies in an agent-based Keynesian model. Journal of Economic Dynamics and Control, 37, 1598-1625.

https://doi.org/10.1016/j.jedc.2012.11.008

Dosi, G., Fagiolo, G., Napoletano, M., Roventini, A., Treibich, T., (2015). Fiscal and monetary policies in complex evolving economies. Journal of Economic Dynamics and Control, 52, 166-189.

http://dx.doi.org/10.1016/j.jedc.2014.11.014

Dosi, G., Pereira, M. C., Roventini, A., Virgillito, M. E., (2017). When more flexibility yields more fragility: The microfoundations of Keynesian aggregate unemployment. Journal of Economic Dynamics and Control, 81, 162-186. http://dx.doi.org/10.1016/j.jedc.2017.02.005

Dosi, G., Pereira, M. C., Roventini, A., Virgillito, M. E., (2018). The effects of labour market reforms upon unemployment and income inequalities: An agent-based model. Socio-Economic Review, 16 (4), 687-720.

Forster, M., Toth, I., (2015). Cross-Country evidence of the multiple causes of inequality changes in the OECD area. In Atkinson A., Bourguignon F. (Eds.), Handbook of income distribution, vol. 2B. Amsterdam, Elsevier.

Geroski, P. (1991). Market dynamics and entry. Oxford, Basil Blackwell.

Grazzini, J., Richiardi, M. G., Sella, L., (2018). The agent-based experiment. In Delli Gatti D., Fagiolo G., Gallegati M., Richiardi M. G., Russo A., (Eds.), Agent-based models in economics: A toolkit. Cambridge University Press. 
Kawasaki, S., McMillan, J., Zimmerman, K., (1982). Disequilibrium dynamics: an empirical study. American Economic Review, 72, 992-1004. http://www.jstor.org/stable/1812018

Lazear, E., (1990). Job security provisions and employment. Quarterly Journal of Economics, 105, 699-726.

Mazzocchetti, A., Raberto, M., Teglio, A., Cincotti, S., (2018). Securitization and business cycle: an agent-based perspective. Industrial and Corporate Change, 27(6), 1091-1121. https://academic.oup.com/icc/article-abstract/27/6/1091/5251886

Myers, S.C., Majluf, N.S., (1984). Corporate financing and investment decisions when firms have information that investors do not have. Journal of Financial Economics, 13, 87-224. https://doi.org/10.1016/0304-405X(84)90023-0

OECD (1994). The OECD jobs study: Evidence and explanations. OECD, Paris.

OECD (2011). Divided we stand. OECD, Paris.

Piketty, T., (2014). Capital in the twenty-first century. The Belknap Press of Harvard University Press, Cambridge (MA)-London.

Riccetti, L., Russo, A., Gallegati, M., (2015). An agent-based decentralized matching macroeconomic model. Journal of Economic Interaction and Coordination, 10(2), 305-332.

https://link.springer.com/article/10.1007/s11403-014-0130-8

Riccetti, L., Russo, A., Gallegati, M., (2016). Financialisation and crisis in an agent based macroeconomic model. Economic Modelling, 52, 162-172. https://doi.org/10.1016/j.econmod.2014.11.028

Russo, A., Riccetti, L., Gallegati, M., (2016). Increasing inequality, consumer credit and financial fragility in an agent based macroeconomic model. Journal of Evolutionary Economics, 26(1), 25-47.

http://link.springer.com/10.1007/s00191-015-0410-z

Saltelli, A., Ratto, M., Andres, T., Campolongo, F., Cariboni, J., Gatelli, D., Saisana, M., Tarantola, S. (2008). Global sensitivity analysis. The primer. John Wiley \& Sons.

Scarpetta, S., (1996). Assessing the role of labour market policies and institutional settings on unemployment: A cross-country study. OECD Economic Studies, 26, 43-98.

Scheidel, W., (2017). The great leveler: Violence and the history of inequality from the stone age to the twenty-first century. Princeton University Press.

Siebert, H., (1997). Labor market rigidities: At the root of unemployment in Europe. The Journal of Economic Perspectives 11, 37-54. http://www.aeaweb.org/articles.php?doi=10.1257/jep.11.3.37

Sutton, J., (1997). Gibrat's legacy. Journal of Economic Literature, 35, 40-59. https://www.jstor.org/stable/2729692 